\title{
Occurrence of lipopolysaccharide alterations among Tn5 mu- tants of Rhizobium leguminosarum bv. trifolii strain 24.1 with altered colony morphology
}

\author{
Sylwia Szyprowska, Adam Choma, Maria Głowacka ${ }^{\varpi}$, Edyta Gronek, \\ Agnieszka Kitlińska and Marzena Rola
}

\section{Department of General Microbiology, M. Curie-Sklodowska University, Lublin, Poland}

Received: 5 March, 1998; accepted: 20 November, 1998

Key words Rhizobium leguminosarum bv, trifolii, Tn5 mutants, defective lipopolysaccharide

\begin{abstract}
Transposon mutants of Rhizobium leguminosarum bv. trifolii 24.1 showing less glossy or smaller colonies were screened for properties usually associated with lipopolysaccharide (LPS) defects in $R$. leguminosarum, i.e. motility, growth rate, tendency to agglutination in liquid media and symbiotic efficiency. Neither any of the above mutants nor the earlier isolated $\mathbf{2 4 . 1 2}$ strain, defective in LPS, showed all these properties changed simultaneously. According to PAGE/sodium deoxycholate analysis the mutant $\mathbf{2 4 . 1 2}$ was the only one producing defective lipopolysaccharide. GC-MS analysis revealed in this mutant qualitative changes in composition of its LPS in comparison with LPS isolated from the parent strain. Other Tn5 mutants produced LPSs similar in composition, however the proportion between LPS I and LPS II differed from that in the parent strain.
\end{abstract}

Lipopolysaccharide (LPS) is an integral part of the outer membrane of Gram-negative bacteria. In rhizobia (Rhizobium, Bradyrhizobium) LPSs are believed to be involved in the development of nitrogen fixing nodules on host plants roots. Rhizobia can invade roots of legumes and form nodules which are centres of symbiotic nitrogen fixation (Mylona et al., 1995; van Rijn \& Vanderleyden, 1995).
The role of LPSs in the development of effective nodules was proved by the isolation and characterization of single gene transposon mutants that were simultaneously defective in lipopolysaccharide structure and symbiotic properties. In general, these defects were restored by a single complementing fragment from gene library of the wild type strains (Brink et al., 1990; Priefer, 1989; Cava et al.,

\footnotetext{
${ }^{8}$ Author for correspondence: Maria Głowacka, Department of General Microbiology UMCS, Akademicka 19, 20-033 Lublin, Poland; tel.: (48 81) 537 5974; fax: (48 81) 5375959 ; e-mail: mikrog@biotop.umcs.lublin.pl
}

Abbreviations: LPS, lipopolysaccharide; EPS, exopolysaccharide; DOC, sodium deoxycholate; GC-MS, gas liquid chromatography-mass spectrometry. 
1989; 1990; Diebold \& Noel 1989). The best characterized (in genetical and chemical aspects) lps transposon mutants are those from Rhizobium leguminosarum bv. viciae strains (Priefer, 1989; Zhang et al., 1992; Hollingsworth et al., 1994; Poole et al., 1994; Allaway et al., 1996) and $R$. leguminosarum bv. phaseoli CE 3, renamed $R$. etli (Noel, et al., 1986; Cava et al., 1989; Diebold \& Noel 1989; Carlson et al., 1995). Tn5 mutants, deficient in LPS, have also been obtained from $R$. leguminosarum bv. trifolii (Brink et al., 1990), Bradyrhizobium japonicum (Stacey et al., 1991) and from other rhizobia (Lopez-Lara et al., 1995).

Rhizobial lipopolysaccharides are composed of lipid A, core oligosaccharide and O-chain polysaccharide. All of them were detected in various wild strains of rhizobia (Carlson et al., $1992 ; 1997)$ but the detailed structure of 0 polysaccharide is known only for a few strains (Wang \& Hollingsworth, 1994; Gil-Serrano et al., 1995). One of them is $R$. leguminosarum bv. trifolii 24.1 whose 0 -polysaccharide structure is almost fully defined (Russa et al., 1996). The strain 24.1 is an effective rhizobial strain that harbors three plasmids of molecular size 180, 300 and $500 \mathrm{~kb}$ (Lorkiewicz et al., 1993). It seemed interesting to obtain lps transposon mutants from this strain, especially that such mutants isolated from $R$. leguminosarum bv. trifolii strains have been rather poorly characterized in comparison with the mutants from other biovars of $R$. le guminosarum (Brink et al., 1990; Breedveld et al., 1993).

\section{MATERIALS AND METHODS}

Isolation of Th5 mutants. $R$. leguminosarum bv. trifolii 24.1 was randomly mutagenized by transposition of Tn5. For this purpose, the parent strain was crossed with Escherichia coli S17.1 containing Tn5 on the plasmid pSUP202.1 (donor cells). Tn5 carrying transconjugants were selected on yeast- mannitol medium 79CA (Vincent, 1970) supplemented with neomycin $(30 \mu \mathrm{g} / \mathrm{ml})$ and rifampicin $(40 \mu \mathrm{g} / \mathrm{ml})$ (Simon et al., 1986).

Characteristics of Th5 mutants. Colony morphology mutants were identified visually on yeast-mannitol medium 79CA. For further studies morphologically changed colonies (with visually altered slime, less glossy, or/and smaller) were chosen. The autoagglutination in 79CA medium was determined after $24 \mathrm{~h}$ of growth. The growth rate was measured as changes in $A_{550}$ after $24 \mathrm{~h}$ of growth. The mutants' motility was estimated on $79 \mathrm{CA}$ plates containing 0.3\% agar (Priefer, 1989). Sensitivities of parent and mutant strains to SDS $(0.005-0.02 \%)$, sodium deoxycholate (DOC) (0.005-0.1\%), Triton X-100 (0.005$0.02 \%$ ), crystal violet $(0.007-0.01 \%)$ and Congo red $(0.05 \%)$ were compared by evaluating the growth of colonies on 79CA agar plates supplemented with proper concentration of these compounds (de Maagd et al., 1989).

Plant test. Nodulation and nitrogen-fixing ability of bacterial strains were tested on Trifolium pratense cv. Hruszowska. Seeds were surface sterilized with $0.2 \% \mathrm{HgCl}_{2}$ and $75 \%$ ethanol and germinated in the dark. Seedlings were then transferred onto nitrogen-free salt medium (Vincent, 1970), inoculated with bacteria, and cultivated for 5 weeks at 10/14 h dark/light period. Symbiotic properties were estimated by the nodulation rate and mass of green part of plants.

DNA analysis. DNA preparations of the parent strain and its mutants were isolated by the modified Eckhardt's method (Eckhardt, 1978) and electrophoresed in $0.7 \%$ agarose gel. Hybridization experiments were carried out with Southern blots using ${ }^{32} \mathrm{P}$-labelled pSUP202.1 as a probe (Sambrook et al., 1989).

LPS analysis. The bacteria grew at $26^{\circ} \mathrm{C}$ for 5 days on 79CA agar plates. Lipopolysaccharides were isolated from cells with $45 \%$ hot phenol/water and purified by repeated ultracentifugation at $105000 \times \mathbf{g}$ (Westphal \& 
Jann, 1965). Polyacrylamide gel electrophoresis (PAGE) was performed with deoxycholate as a detergent (Krauss et al., 1988). The gels were silver-stained according to Tsai \& Frasch (1982). Sugar composition of the LPS samples was determined according to Russa et al. (1996).

\section{RESULTS AND DISCUSSION}

\section{Isolation and characteristics of Tn5 mutant}

Selection of Rhizobium mutants with altered lipopolysaccharides is difficult due to lack of a direct selection method. Such types of mutants were selected after Tn5 mutagenesis from among numerous screened kanamycin resistant colonies, basing on colony morphology (Priefer, 1989) or due to their altered reactions with antibodies (de Maagd et al.,1989), and from among clones defective in symbiotic properties (Noel et al., 1986; Cava et al., 1989). Tn5 mutants with altered lipopolysaccharide structure, isolated from different $R$. leguminosarum strains usually showed various simultaneously changed properties when compared with wild type strains. Such mutants formed mostly rough or less glossy colonies, showed a tendency to autoagglutinate in liquid media and lost their motility (Noel et al.,1986; Cava et al., 1989; de Maagd et al., 1989; Priefer, 1989; Brink et al.,1990; Rae et al., 1991; Poole et al., 1994). $R$. leguminosarum bv. trifolii $\mathrm{Tn} 5$ mutants with reduced LPS structure grew at slower rate in liquid media than the wild type strain (Brink et al.,1990).

Taking these data into consideration we tried to find lipopolysaccharide mutants of $R$. leguminosarum bv. trifolii 24.1 from among Tn5 clones showing changes in the following properties: colony morphology, growth ratio in liquid media, defects in motility, and symbiotic efficiency. Strain 24.1 was mutagenized with Tn5 in a series of matings with $E$. coli S17.1 pSUP202.1 as a donor strain. Antibi- otic resistant colonies were obtained with a frequency of $10^{-6}-10^{-7}$ per recipient. From among the total number of several hundred clones those showing changed colony morphology (visually decreased slime production or less glossy colonies) were chosen for further characterization. As reference strains the wild type 24.1 as well as the earlier isolated 24.12 Tn5 mutant with reduced amount of O-polysaccharide in its LPS (Głowacka et al., 1996) were used. None of the mutants formed rough colonies but all of them showed a tendency to autoagglutinate in yeast-mannitol medium (Table 1). All strains were motile in $0.3 \%$ agar, but the zone diameter was much smaller in the case of mutant 24.10. The strain 24.12 , known to be lipopolysaccharide deficient, formed a lot of slime, was motile in $0.3 \%$ agar and its growth rate was much lower in comparison with parent strain 24.1.

Lipopolysaccharide defective mutants of $R$. leguminosarum showed also increased susceptibility to dyes and surface active agents, which probably result from changes in the outer membrane organization (de Maagd et al., 1989). Tn5 mutants isolated from strain 24.1 were also tested for sensitivity to DOC, SDS, Triton X-100, crystal violet and Congo red. Only mutant 24.12 did not grow on 79CA agar plates supplemented with $0.01 \%$ SDS and $0.01 \%$ Triton X-100, while other mutants were not more sensitive than strain 24.1.

Symbiotic properties of mutants were compared with those of the parent strain 24.1 in tube test with $T$. pratense as a host plant. None of the known $R$. leguminosarum Tn5 mutants with defective LPS could establish normal effective nodules. In the case of $R$. leguminosarum forming indeterminate nodules, their Tn5 mutants with defective LPS pro duced mostly non-effective nodules with none or very low nitrogenase activity (Priefer, 1989; Poole et al., 1994; de Maagd et al., 1989; Brink et al., 1990; Perotto et al., 1994). Moreover, some delay in nodulation was also observed (Brink et al., 1990) as well as production of abortive nodules evidenced as small 
Table 1. Characteristics of $R$. leguminosarum bv. trifolii 24.1 transposon mutants.

Growth rate expressed in $\mathrm{A}_{550}$ and intensity of precipitation determined after $24 \mathrm{~h}$ in yeast mannitol medium. $\mathrm{A}_{550}$ at 0 time was $0.02-0.04$ in all cases. Motility measured in the same medium containing $0.3 \%$ agar.

\begin{tabular}{|c|c|c|c|c|c|c|}
\hline Strain & $\begin{array}{l}\text { Growth } \\
\text { rate }\end{array}$ & $\begin{array}{l}\text { Autoagglu- } \\
\text { tination }\end{array}$ & $\begin{array}{c}\text { Motility } \\
\text { (diameters of } \\
\text { zones in } \mathrm{mm} \text { ) }\end{array}$ & $\begin{array}{l}\text { Symbiotic } \\
\text { phenotype }\end{array}$ & $\begin{array}{c}\text { Average nodule } \\
\text { number/ } \\
\text { plant after } \\
\text { 2 weeks }\end{array}$ & $\begin{array}{c}\text { Average green } \\
\text { mass of plant } \\
\text { (mg) }\end{array}$ \\
\hline 24.1 & 0.195 & - & 30 & Nod Fix $^{+}$ & 6.2 & 143.2 \\
\hline 24.12 & 0.070 & + & 28 & Nod $^{-}$ & - & $34.5^{\circ}$ \\
\hline 24.9 & 0.190 & ++ & 30 & $\mathrm{Nod}^{+} \mathrm{Fix}^{+}$ & 2.5 & $111.0^{\circ}$ \\
\hline 24.10 & 0.071 & H+ & 9.5 & $\mathrm{Nod}^{+} \mathrm{Fix}^{+}$ & 3.2 & $72.3^{\circ}$ \\
\hline 24.11 & 0.187 & ++ & 22.5 & Nod $^{+} \mathrm{Fix}^{+}$ & 2.7 & $66.5^{\circ}$ \\
\hline 24.14 & 0.214 & H+ & 28 & $\mathrm{Nod}^{+} \mathrm{Fix}^{+}$ & 3.6 & $101.8^{\circ}$ \\
\hline 24.16 & 0.145 & ++ & 25 & Nod $^{+} \mathrm{Fix}^{+}$ & 7.0 & 134.3 \\
\hline 24.22 & 0.135 & ++ & 26.5 & Nod $^{+} \mathrm{Fix}^{+}$ & 6.5 & 136.1 \\
\hline 24.25 & 0.135 & ++ & 20 & Nod $^{-}$ & - & $31.3^{*}$ \\
\hline 24.62 & 0.215 & ++ & 27.5 & Nod Fix $^{+}$ & 4.4 & $77.3^{*}$ \\
\hline 24.65 & 0.060 & ++ & 20 & $\mathrm{Nod}^{-}$ & - & $23.2^{\circ}$ \\
\hline 24.71 & 0.132 & ++ & 27 & $\mathrm{Nod}^{+} \mathrm{Fix}^{+}$ & 4.3 & $103.4^{\circ}$ \\
\hline
\end{tabular}

"Difference from the control plants at $P<0.05$ (Student's $t$ test.

tissue proliferations (Perotto et al., 1994). In our studies potential nodulation was presented as the average number of nodules two weeks after infection. Symbiotic efficiency was measured as the yield of green mass of plants. As can be seen from Table 1 the mutants $24.12,24.25$ and 24.65 were unable to nodulate and the average green mass of plants infected with these strains reached only about $30 \%$ of the average green mass of plants infected with the parental strain 24.1. Other mutants produced fewer nodules after two weeks than 24.1 (except 24.16 and 24.22), but the nodules were effective. Average green masses of plants infected with mutants 24.9 , $24.10,24.11,24.14,24.62,24.71$ were significantly different from those of plants inoculated with the parent strain, which seemed to point to decreased a symbiotic efficiency. None of the Tn5 mutants tested showed all the characteristics that had been observed earlier in LPS mutants of $R$. leguminosarum but neither did the mutant 24.12 defective in
LPS. The clone designated 24.10 possessed most of the changed properties. The mutant 24.65 grew poorly in liquid medium reaching $\mathrm{A}_{550}$ of 0.06 after $24 \mathrm{~h}$ similarly as 24.12 and 24.10. Nonnodulating clones 24.12, 24.25, 24.65 and also 24.10 were chosen for further characterization. Agarose gel electrophoresis showed that nonnodulating strains were deprived of the smallest plasmid designated pSym in 24.1 strain (Lorkiewicz et al., 1993). Hybridization with $\operatorname{Tn} 5$ as a probe demonstrated that the transposon was localized on two nonsymbiotic plasmids ( 300 and $500 \mathrm{~kb}$ ) in mutant 24.10 and on one nonsymbiotic plasmid $(300 \mathrm{~kb}$ ) in mutant 24.12 (Fig.1). The mechanism of genetic control of lipopolysaccharide synthesis is not known in detail yet, but the genes involved are localized on nonsymbiotic plasmids in different strains. It has been also suggested that the $\operatorname{lps} \beta$ region is highly conserved in plasmids of $R$. leguminosarum and $R$. etli (Hynes \& McGregor, 1990; Garcia et al., 1996; Brom et al., 1992). Most 


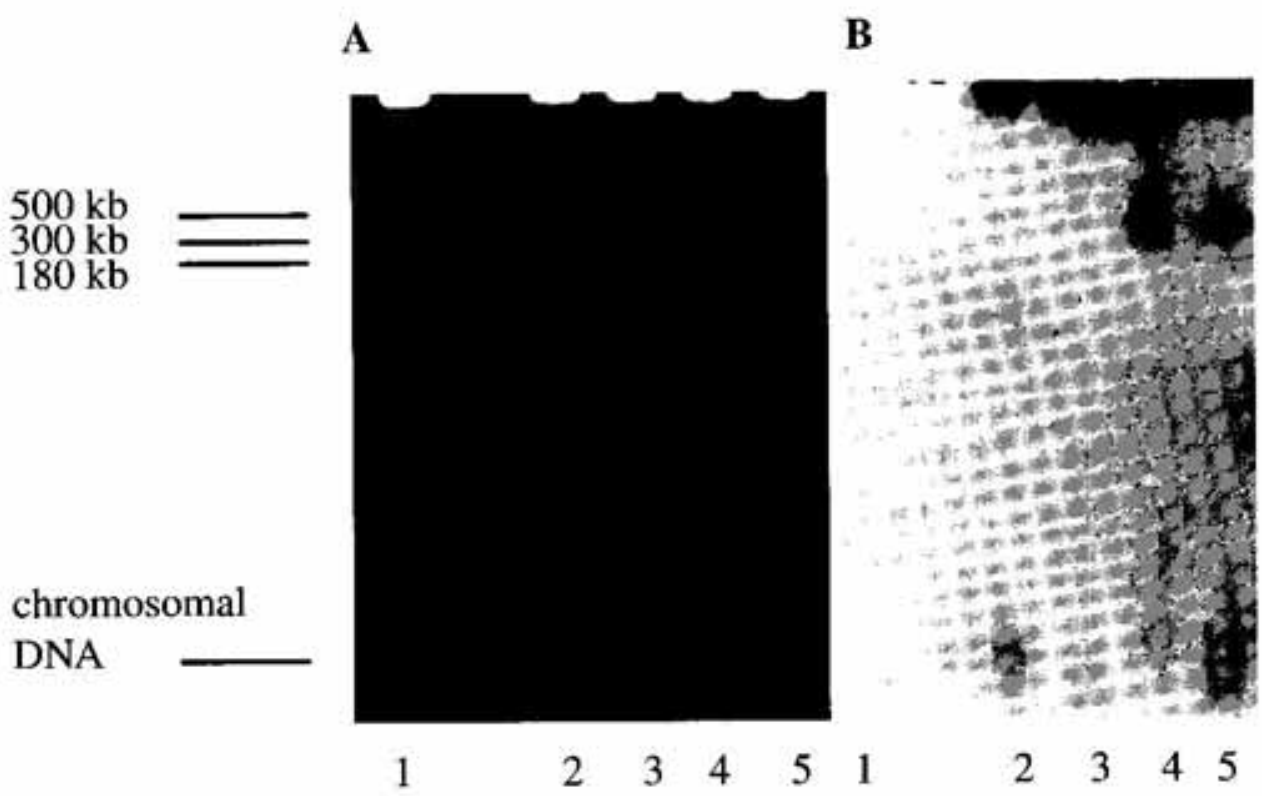

Figure 1. A. Agarose gel electrophoresis of plasmid DNA in strains of $R$. leguminosarum bv. trifolii. B. Southern blot hybridized with ${ }^{32}$ P-labeled probe of pSUP202.1.

Lane 1, 24.1; lane 2, 24.25; lane 3, 24.65; lane 4, 24.10; lane 5, 24.12. Sizes of plasmids were described according to Lorkiewicz et al. (1993).

probably the presence of a symbiotic plasmid is not essential for LPS biosynthesis. The Tn5 mutant defective in LPS was isolated from $R$. leguminosarum biovar trifolii strain cured of pSym (RBL5515). This mutant remained nonnodulating even when pSym (pRLJI) was reintroduced into it. When pSym was reintroduced into nonmutagenized RBL 5515 strain formation of nitrogen fixing nodules (Breedveld et al., 1993) was induced.

\section{Characterization of lipopolysaccharides}

In the next step of investigations lipopolysaccharides of chosen mutants were characterized by PAGE/DOC and chemical analysis. LPS preparations of strain 24.1 and mutants $24.9,24.10,24.12,24.14,24.25,24.65,24.71$ were separated by PAGE/DOC and visualized by silver staining (Krauss et al., 1988; Tsai \& Frasch, 1982). Two forms of rhizobial lipopolysaccharides are visualized by this procedure: LPS I, a high molecular form containing lipid A, core and O-polysaccharide, and LPS II, a fast migrating oligosaccharide composed of lipid A and core only. From among LPSs tested that of the mutant 24.12 was apparently different from that of the parent strain. This mutant was believed to be completely deprived of O-side chains in LPS (Glowacka et $a l ., 1996)$ but in further experiments a poorly visible band migrating slower than that of LPS II was observed when an excess of the LPS preparation was loaded on PAGE/DOC. However, LPS II was the main compound of this LPS preparation visible on polyacrylamide gel (Fig. 2). Additionally, it seems that the core of LPS of 24.12 is different from that of the parental strain, because in PAGE/DOC analysis LPS II migrated faster than in strain 24.1 and its other derivatives (Fig. 2). Sugar composition of LPS preparations was analysed additionally by GC-MS (Table 2). All preparations isolated using the phenol/water method (Westphal \& Jann, 1965) contained quite large amounts of glucose which sug. gested contamination with exopolysaccharide (EPS) or glucans. An extremely high content of glucose (about $60 \mathrm{~mol} \%$ ) EPS was found in 24.12 LPS. Two, independently isolated, LPS 
Table 2. Sugar composition of LPS preparations in mol \%.

All LPS preparations were carboxy-reduced with natrium borodeuteride according to Russa et al. (1996). The contents of Gal and GalA as well as Glc and GlcA were calculated from the peak areas at $289 \mathrm{~m} / z$ and $291 \mathrm{~m} / \mathrm{z}$, respectively. The content of GlcN and GlcNA was calculated from the areas at $145 \mathrm{~m} / \mathrm{z}$ and $146 \mathrm{~m} / \mathrm{z}$, respectively.

\begin{tabular}{lccccccc}
\hline & \multicolumn{7}{c}{ Strain } \\
\cline { 2 - 7 } Component & 24.1 & 24.12 & 24.10 & 24.65 & 24.25 & 24.9 & 24.71 \\
\hline 6-Deoxy-L-talose & 9.3 & 1.0 & 8.53 & 9.20 & 17.22 & 10.46 & 8.65 \\
L-Rhamnose & 17.2 & 1.7 & 19.65 & 20.00 & 18.92 & 21.25 & 18.43 \\
2,3 Di-O-methylgalactose & 1.6 & 0.3 & 1.27 & 1.31 & 3.31 & 1.32 & 1.18 \\
Quinovosamine & 1.4 & 0.4 & 1.28 & 2.31 & 1.46 & 1.15 & 1.54 \\
D-Mannose & 5.2 & 0.4 & 3.70 & 5.34 & 8.49 & 3.09 & 4.27 \\
D-Glucose & 17.75 & 56.91 & 22.60 & 18.72 & 9.57 & 24.77 & 22.53 \\
D-Glucuronic acid & 0.46 & 16.69 & 3.38 & 0 & 0.58 & 0 & 1.30 \\
D-Galactose & 6.01 & 5.85 & 11.13 & 7.29 & 10.02 & 13.71 & 4.49 \\
D-Galacturonic acid & 11.49 & 5.80 & 12.06 & 11.90 & 10.02 & 5.87 & 10.49 \\
3-Deoxy-2-heptulosaric acid & 6.8 & 0.4 & 5.14 & 6.53 & nd & 7.84 & 5.89 \\
D-Glucosamine & 0.76 & 2.65 & 3.41 & 2.84 & 3.49 & 2.48 & 2.52 \\
D-Glucosaminic acid & 0.64 & 2.65 & 1.84 & 2.41 & 3.79 & 1.26 & 2.06 \\
D-Galactosamine & nd & nd & 0.80 & 0.68 & nd & nd & nd \\
Heptose & nd & 1.0 & nd & nd & nd & nd & nd \\
2-Keto-3-deoxyoctonate & 8.3 & 3.4 & 4.0 & 7.25 & 0.37 & 4.47 & 4.83 \\
\hline
\end{tabular}

nd, not detected

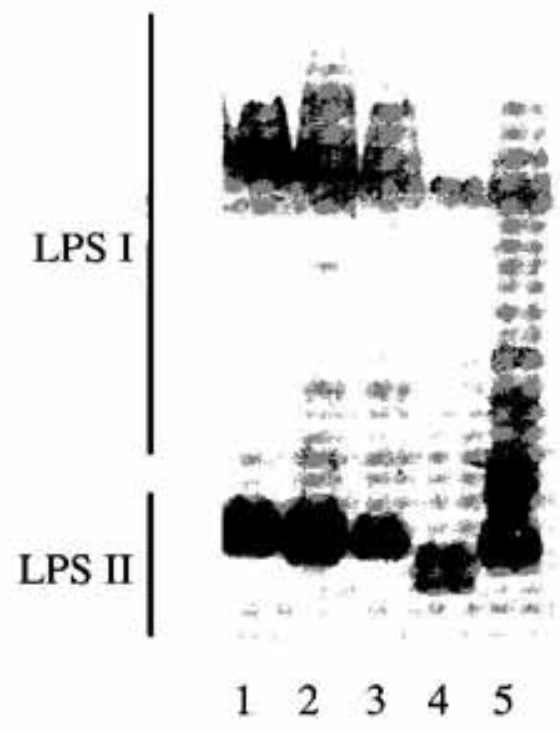

Figure 2. Electrophoretic migration patterns of LPS from $R$. leguminosarum bv. trifolii 24.1 and its mutants obtained in PAGE/DOC and silver staining.

Lane 1, 24.25; lane 2, 24.65; lane 3, 24.10; lane 4, 24.12; lane 5 24.1. preparations from this strain were analyzed (not shown). In both preparations, a small amount (0.48-1.7 mol \%) of rhamnose was also detected. In one preparation traces of 6 deoxy-L-talose and 3-deoxy-2-heptulosamic acid were also present ( 1.0 and $0.4 \mathrm{~mol} \%$, respectively). These results indicate that in the strain 24.12 the amount of O-polysaccharide in LPS was strongly reduced. D-Glucosamine was accompanied by a similar amount of D-glucosaminic acid pointing to lipid $\mathrm{A}$ as an origin of both these compounds (Bhat et al., 1994). The ratio of rhamnose (component of O-side chain) and GlcN+GlcNA (derived from lipid A) in strain 24.12 was less than $1(0.32$ and 0.15 in the first and second preparation, respectively). These results confirmed the data from PAGE showing that, in this strain, LPS II is the main component of LPS preparation. This LPS preparation contained 1.0 mol \% of heptose, a component not found in 
other preparations. It had been earlier observed that in some nonnodulating derivatives of strain 24.1 the lipopolysaccharides are rich in heptose (Lorkiewicz et al., 1993). Strain 24.12 produced a lot of EPS unlike most known $R$. leguminosarum Tn5 lps mutants. However, in one of the mutants, RBL5515 lps-336 production of a normal amount of EPS was observed (Breedveld et al., 1993). It should be concluded that, in $R$. leguminosarum biovar trifolii, defects in lipopolysaccharide are not always correlated with rough colony morphology and/or other properties discussed in this paper.

Components different from those of the wild type strain were not detected in the analyzed lipopolysaccharides. Their basic composition did not show significant differences irrespectively of additional characteristics suggesting the presence of LPS defects (24.10) or pSym absence $(24.25,24.65)$. However, all of the mutant strains produced LPSs which probably contained a diminished proportion of components in their O-polysaccharide parts. Ratios of rhamnose to glucosamine+glucosaminic acid were 2.59 (strain 24.25) - 5.18 (strain 24.9), while the ratio in 24.1 LPS preparations was about 12 .

Experiments on a non symbiotic plasmid for identifying a region carrying the Tn5 insertion in the 24.12 strain, as well as investigation on detailed structure of its LPS will be continued.

We would like to thank Prof. R. Russa and Dr. T. Urbanik-Sypniewska for helpful discussion. We also acknowledge technical assistance of Ms M. Szlachetka.

\section{R EF E R E N CES}

Allaway, D., Jeyaretnam, B., Carlson, R.W. \& Poole, P.S. (1996) Genetic and chemical characterization of a mutant that disrupts synthesis of the lipopolysaccharide core tetrasaccharide of $R$. leguminosarum. J. Bacteriol. 178, 6403-6406.
Bhat, U.R., Forsberg, L.S. \& Carlson, R.W. (1994) Structure of lipid A component of $R$. legumi. nosarum bv. phaseoli lipopolysaccharide. J. Biol. Chem. 269, 14402-14410.

Breedveld, M.W., Canter Cremers, H.C.J., Batley, M., Posthumus, M.A., Zavenhuizen, L.P.T.M., Wijffelman, C.A. \& Zehnder, A.J.B. (1993) Polysaccharide synthesis in relation to nodulation behavior of Rhizobium leguminosarum. J. Bacteriol. 175, 750-757.

Brink, B.A., Miller, J., Carlson, R.W. \& Noel, K.D. (1990) Expression of Rhizobium leguminosarum CFN42 genes for lipopolysaccharide in strains derived from different $R$. leguminosarum soil isolates. J. Bacteriol. 172, 548-555.

Brom, S., Garcia de los Santos, A., Stępkowski, T., Flores, M., Davila, G., Romero, D. \& Palacios, R. (1992) Different plasmids of Rhizobium leguminosarum bv. phaseoli are required for optimal symbiotic performance. J. Bacteriol. 174, 5183-5189.

Cava, J.R., Elias, P.M., Turowski, D.A. \& Noel, K.D. (1989) $R$. leguminosarum CNF42 genetic regions encoding lipopolysaccharide structures essential for complete nodule development on bean plants. J. Bacteriol. 171, 8-15.

Cava, J.R., Tao, H. \& Noel, K.D. (1990) Mapping of complementation groups within a Rhizobium leguminosarum CNF42 chromosomal region required for lipopolysaccharide synthesis. Mol. Gen. Genet. 221, 125-128.

Carlson, R.W., Reuhs, B.R., Chen, T.B., Bhat, U.R. \& Noel, K.D. (1995) Lipopolysaccharide core structures in Rhizobium etli mutants deficient in O-antigen. J. Biol. Chem. 270, 11783-11788.

Carlson, R.W., Bhat, U.R. \& Reuhs, B. (1992) Rhizobium lipopolysaccharides; their structures and evidence for their importance in the nitrogen-fixing symbiotic infection of their host legumes; in, Biotechnology and Development Plant. 2 (Gresshoff, P.M., ed.) pp. 33-43, CRC Press, Boca Raton.

Carison, R.W., Forsberg, L.S., Kannenberg, E., Jeyaretnam, B. \& Reuhs, B. (1997) Rhizobial capsular and lipopolysaccharides: Evidence for their importance in Rhizobium-legume symbiosis; in Biological Fixation of Nitrogen 
for Ecology and Sustainable Agriculture (Legocki, A., Bothe, H. \& Phler, A., eds.) pp. 101-106, NATO ASI series vol. G 39. Springer-Verlag, Berlin, Heidelberg.

Eckhardt, T. (1978) A rapid method for the identification of plasmid deoxyribonucleic acid in bacteria. Plasmid 1, 584-588.

Diebold, R. \& Noel, K.D. (1989) Rhizobium leguminosarum exopolysaccharide mutants: Biochemical and genetic analyses and symbiotic behavior on three hosts. J. Bacteriol. 171, 4821-4830.

Garcia-de los Santos, A., Brom, S. \& Romero, D. (1996) Rhizobium plasmids in bacteria-legume interactions. World J. Microbiol Biotech nol. 12, 119-125.

Gil-Serrano, A.M., Gonzales-Jimenez, I., Mateo, P.T., Bernabe, M., Jimenez-Barbero, J., Megias, M. \& Romero-Vazquez, M.J. (1995) Structural analysis of the 0-antigen of the lipopolysaccharide of Rhizobium tropici CIAT 899. Carbohydr. Res. 275, 285-294.

Głowacka, M., Stẹpień, A. \& Szyprowska, S. (1996) The effect of exogenous rhizobial lipopolysaccharide on symbiosis of Rhizobium le guminosarum bv. trifolii with red clover. Acta Soc. Botanic. Polon., 66, 307-309.

Hollingsworth, R.I., Zhang, Y. \& Priefer, U.B. (1994) Structure of the unusual trisaccharide lipopolysaccharide component produced by a symbiotically defective mutant of Rhizobium leguminosarum biovar viciae. Carbohydr. Res. 264, 271-280.

Hynes, M.F. \& McGregor, N.F. (1990) Two plasmids other than the nodulation plasmid are necessary for formation of nitrogen-fixing nodules by Rhizobium leguminosarum. Mol. Microbiol. 4, 567-574.

Krauss, J.H., Weckesser, J. \& Mayer, H. (1988) Electrophoretic analysis of lipopolysaccharides of purple nonsulfur bacteria. Int. J. Sys. tem. 38, 157-163.

Lopez-Lara, I.M., Orgambide, G., Dazzo, F.B., Olivares, J. \& Toro, N. (1995) Surface polysaccharide mutants of Rhizobium sp. (Acacia) strain GRH2: Major requirement of lipopolysaccharide for successful invasion of Acacia nodules and host range determination. Microbiology 141, 573-581.

Lorkiewicz, Z., Deryło, M., Russa, R., Skorupska, A. \& Urbanik-Sypniewska, T. (1993) Rhizobium leguminosarum biovar trifolii mutants altered in surface structures that are defective in nodulation or nitrogen fixation. Acta Microbiol. Polon. 42, 219-234.

de Maagd, R.A., Rao, A.S., Mulders, I.H.M., Goosen-de Roo, L., van Loosdrecht, M.C.M., Wijffelman, C.A. \& Lugtenberg, B.J.J. (1989) Isolation and characterization of mutants of Rhizobium leguminosarum bv. viciae 248 with altered lipopolysaccharides, possible role of surface charge or hydrophobicity in bacterial release from the infection thread. J. Bacteriol. 171, 1143-1150.

Mylona, P., Pawłowski, K. \& Bisseling, T. (1995) Symbiotic nitrogen fixation. Plant Cell 7, 869-885.

Noel, K.D., Vandenbosch, K.A. \& Kulpaca, B. (1986) Mutations in Rhizobium phaseoli that lead to arrested development of infection threads. J. Bacteriol. 168, 1392-1401.

Perotto, S., Brewin, N.J. \& Kannenberg, E.L. (1994) Cytological evidence for a host defense response that reduces cell and tissue invasion in pea nodules by lipopolysaccharide-defective mutants of Rhizobium leguminosarum strain 3841. Molec. Plant-Microbe Interact. 7, 99-112

Poole, P.S., Schofield, N.A., Reid, C.J., Drew, E.M. \& Walshaw, D.L. (1994) Identification of chromosomal genes located downstream of $d c t \mathrm{D}$ that affect the requirement for calcium and the lipopolysaccharide layer of Rhizo. bium leguminosarum. Microbiology 140, 2797-2809.

Priefer, U.B. (1989) Genes involved in lipopolysaccharide production and symbiosis are clustered on the chromosome of Rhizobium legu. minosarum biovar viciae VF39. J. Bacteriol. 171, 6161-6168.

Rae, A.L., Perotto, S., Knox, J.P., Kannenberg, E.L. \& Brewin, N.J. (1991) Expression of extracellular glycoproteins in the uninfected cells of developing pea nodule tissue. Molec. Plant-Microbe Interact., 4, 563-570. 
van Rhijn, P. \& Vanderleyden, J. (1995) The Rhizobium plant symbiosis. Microbiol. Rev. 59, 124-142.

Russa, R., Urbanik-Sypniewska, T., Shashkow, A.S., Banaszek, A., Zamojski, A. \& Mayer, H. (1996) Partial structure of lipopolysaccharides isolated from Rhizobium leguminosarum bv. trifolii and its GalA-negative $\mathrm{Exo}^{-}$mutant AR20. System. Appl. Microbiol 19, 1-8.

Sambrook, J., Fritsch, E.F. \& Maniatis, T. (1989) Molecular Cloning. A Laboratory Mannual. Cold Spring Harbor Laboratory Press, New York.

Simon, R., O'Connell, M., Labes, M. \& Phler, A. (1986) Plasmid vectors for the genetic analysis and manipulation of rhizobia and other gram-negative bacteria. Methods Enzymol. 118, 640-659.

Southern, E.M. (1975) Detection of specific sequences among DNA fragments separated by gel electrophoresis. J. Bacteriol. 38, 503-519.

Stacey, G., So, J.-S., Roth, L.E., Bhagya, Lakshmi, S.K. \& Carlson, R.W. (1991) A lipopolysaccharide mutant of Bradyrhizobium japonicum that uncouples plant from bacterial differentia. tion. Molec. Plant-Microbe Interact. 4, 332-340.

Tsai, C.N. \& Frasch, C.E. (1982) A sensitive silver stain for detecting lipopolysaccharides in polyacrylamide gels. Anal. Biochem. 119, 115-119.

Vincent, J.M. (1970) A manual for the practical study of root-nodule bacteria. IBH Handbook No. 5. Blackwell Sci. Publ., Oxford.

Wang, Y. \& Hollingsworth, R.I. (1994) The structure of the O-antigenic chain of the lipopolysaccharide of Rhizobium trifolii 4s. Carbohydr. Res. 260, 305-317.

Westphal, O. \& Jann, K. (1965) Bacterial lipopolysaccharides extraction with phenol-water and further applications of the procedure. Meth ods Carbohydr. Chem. 5, 83-91.

Zhang, Y., Hollingsworth, R.I. \& Priefer, U.B. (1992) Characterization of structural defects in the lipopolysaccharides of symbiotically im. paired Rhizobium leguminosarum bv. viciae VF39 mutants. Carbohydr. Res. 231, 261271. 